\title{
ANNULAR PERIPHERAL RETINAL DETACHMENT*
}

BY

\author{
H. B. STALLARD
}

London

“Things that seem are not the same" (Old Wives' Tale, George Peele, 1595).

WHILST diagnostic mistakes are sometimes eventually to the advantage of a patient, those which result in the unnecessary loss of an eye are not. There is a peculiar type of retinal detachment, which is likely to involve the choroid also, which is annular, peripheral, and so dark in colour (Fig. 2, overleaf) that it is sometimes mis-diagnosed as a " ring sarcoma of the choroid".

\section{Clinical Features}

The detachment has a rolled appearance, in places it is festooned, and in some cases looks not unlike retinal cysts immediately adjacent to each other and unusually dark in colour (Fig. $1 a$ and $b$, overleaf). The posterior limit of the detachment is a gentle undulating line, beyond which there was in one case (Fig. 2) a shallow separation of the retina in the upper nasal quadrant, and in another a shallow separation in the lower nasal quadrant having the pale grey features of a simple retinal separation. Near the ora serrata were some irregular white striae, and anterior to these some very thin degenerate areas which it was impossible to diagnose with certainty as holes, for the red reflex showing through these thin patches was not the brilliant orange red of the choroid seen through a real tear. In one patient little tongues of pigment from the ciliary body projected in a dentate manner around the peripheral circumference of the'retinal detachment (Fig. 3, overleaf).

\section{Material}

Both eyes were affected in three out of six patients (Fig. $1 a$ and $b$ ) and one of these, a Jugoslav sea-captain, had had one eye excised in New York in 1942 in the belief that it contained a ring sarcoma of the choroid. He was referred to me in 1949 for irradiation of the remaining eye (Fig. 1). Another patient had lost one eye, and in the other two patients the second eye has not been so far affected.

In one of these bilateral cases (Fig. $1 a$ and $b$ ), the epibulbar vessels were congested and there were benign melanomata of the conjunctiva at the limbus in both eyes.

All six patients were male European men with dark colouring and hair. Their ages when the disorder was first noted were:

(i) 30; (ii) 32 one eye, 39 the other eye; (iii) 45; (iv) 47; (v) 59; (vi) 60.

* Received for publication October 6, 1953. 


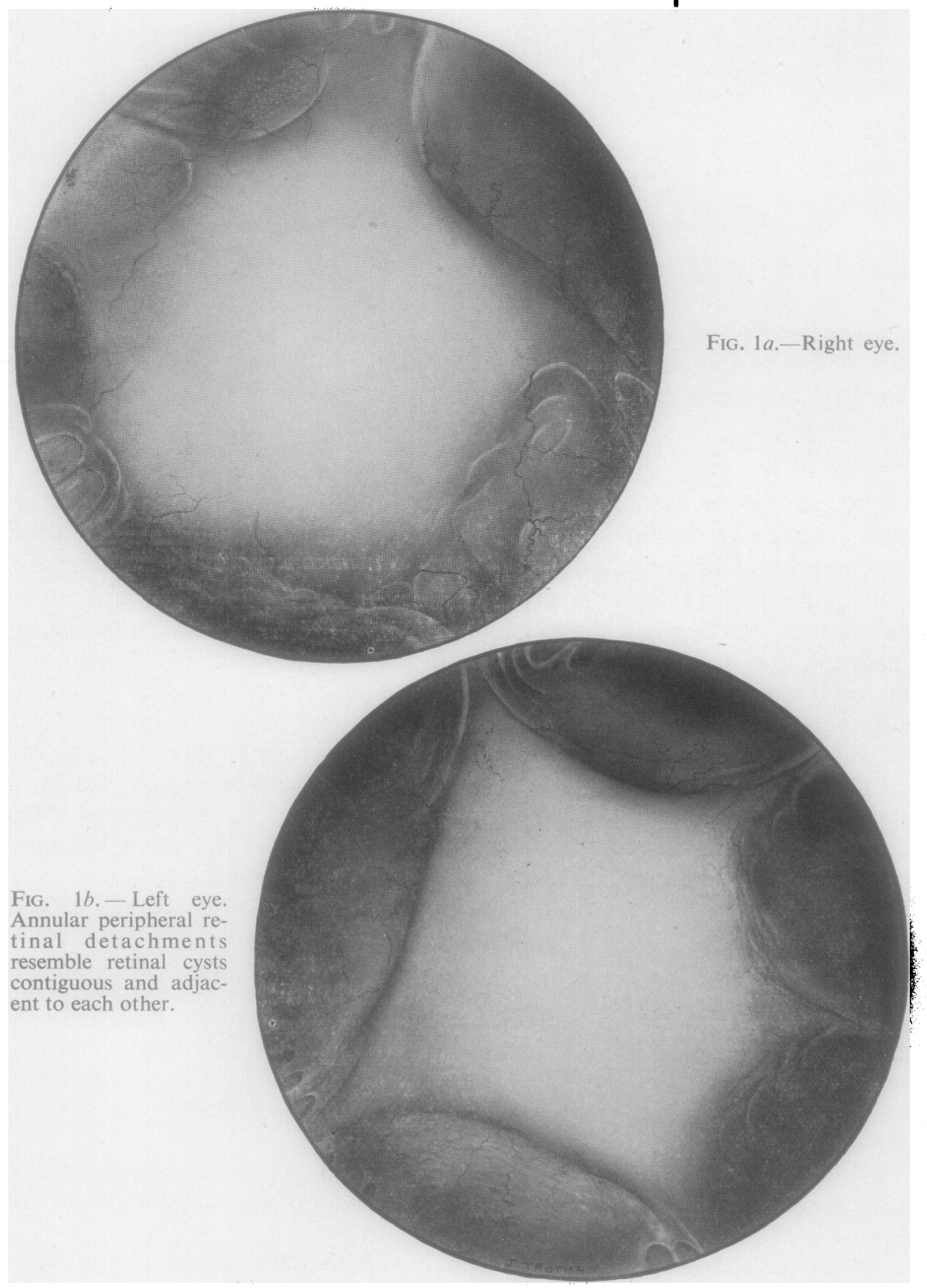

Their occupations were sea-captain, baker, painter, farmer, and engineerso varied as to have no aetiological significance. 


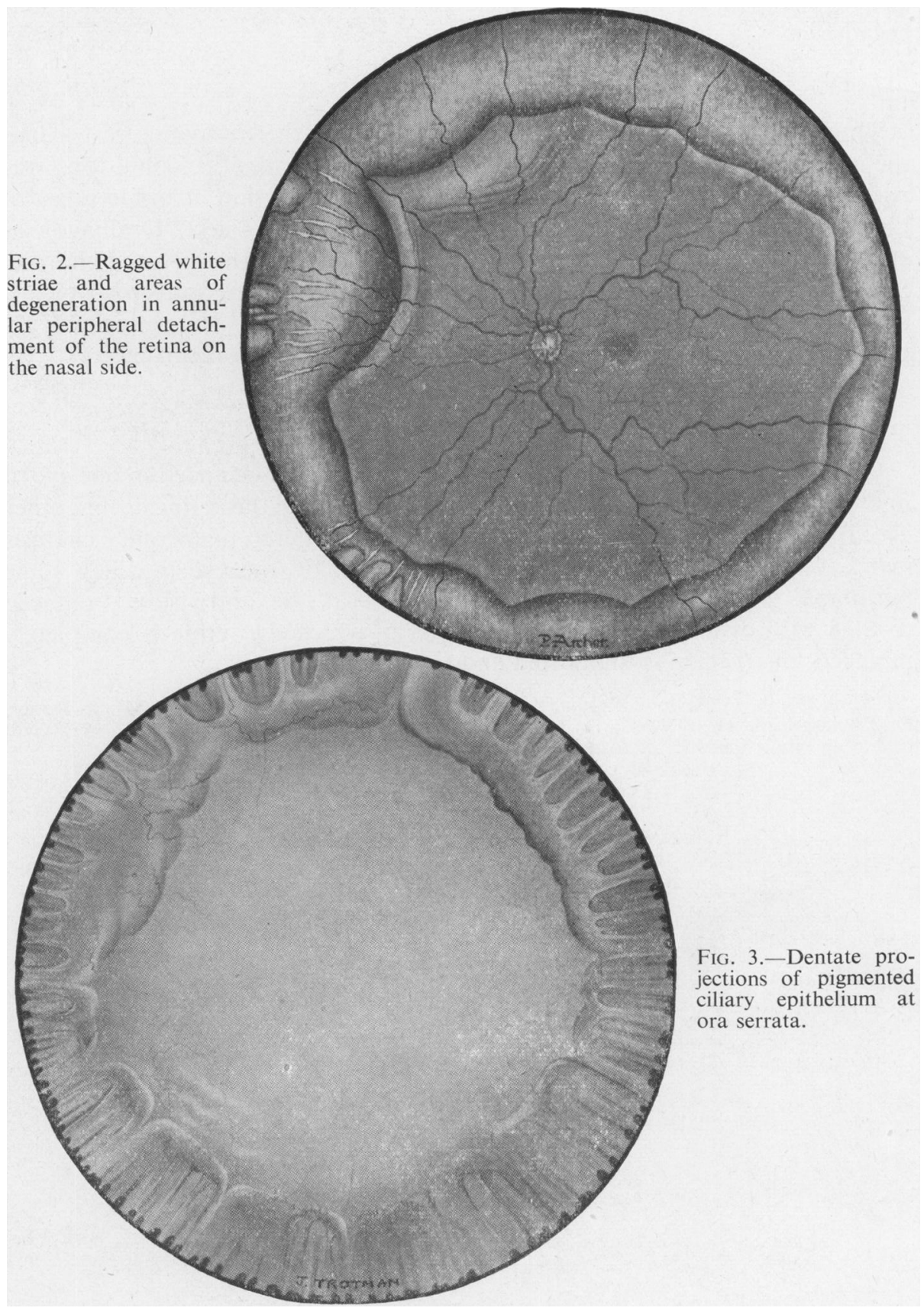

\section{Pathological Investigations}

Pathological investigations showed a raised lymphocyte count to 40 per cent. in one patient, the blood sedimentation rate and plasma proteins were normal. A search for evidence of Boeck's sarcoidosis revealed nothing resembling this disease, 
and radiographic examinations of the chest and accessory nasal air sinuses were negative.

\section{Response to Surgery}

Three of these patients were operated on by diathermy puncture because the condition was progressing. All did well. A terminal 0.5-mm. long was passed through the sclera to the choroid around the thin atrophic areas of the retina and a current of 60-70 ma. was passed for $4 \mathrm{sec}$. Drainage was effected by penetrating diathermy the needle passing through the choroid. Suction was applied and the fluid removed looked no different macroscopically from that removed from a simple retinal detachment. The retina was replaced by a single operation and there has so far been no recurrence

\section{Spontaneous Recovery}

Complete spontaneous replacement of the retina has occurred in one eye of one of the bilateral cases and partial replacement of the retina in his other eye. In both eyes of this patient there are now scattered pigmentary changes in the retina. These are present at the macula in the eye in which some peripheral retinal separation persists on the nasal side, and vision is reduced to $6 / 18$ with distortion. In his other eye, in which the retina is completely replaced, the macula is unaffected and the vision is $6 / 5$.

I thank Dr. A. Filipovic of Rejeka, Yugoslavia, for referring one patient, and Mr. A. Rutter, Dr. Davidson, and Dr. D. McCarthy for sending others. Mr. E. F. King and Mr. J. E. M. Ayoub have each kindly allowed me to refer to one of their patients. 